\title{
DEVELOPMENT OF AN IMPROVED CASSAVA PEELING MACHINE
}

\author{
Akene Alexander \\ Department of Mechanical Engineering, Federal \\ University of Petroleum Resources, Effurun, Nigerian
}

\author{
Oghenevwaire Iyabo Sefiyat \\ Department of Mechanical Engineering, Federal \\ University of Petroleum Resources, Effurun, Nigeria
}

\author{
Anisha Ifeanyi Samuel \\ Directorate of Service, Department of Mechanical Engineering, \\ Petroleum Training Institute, Effurun, Nigeria
}

\begin{abstract}
Cassava is an important staple food crop in sub-Sahara Africa countries such as Nigeria. Regardless of Nigeria be the highest producer of cassava in the world, enough quantities have not been process for storage. However, before cassava can be consumed or used industrially as a raw material, it must pass through initial processing such as peeling, grating, dewatering or pressing, fermenting, sieving, frying and drying. Nevertheless, of all the processing technique, peeling is the most difficult and time consuming operation. In Nigeria mechanization of other processes are successfully except peeling. This necessitated the continuously researching on cassava peeling machine mainly to improve its peeling efficiency. In this present research work, the machine which is batch processing equipment has a capacity of $50 \mathrm{~kg}$ per batch. The peeler drum has a dimension of 600 $\mathrm{mm} \times 800 \mathrm{~mm}$ and it rotates between 30rpm to 100rpm. In a way of improving on existing peeling machine, a stainless steels material was used to replace mild steel used by other researchers and this enhances corrosion prevention and also improves the service life as well as durability. Another aspect of this design that has improved its performance is the inclusion of abrasive ball of different sizes. The balls are 50, 40, 30 and $20 \mathrm{~mm}$ in diameter, which enable the balls to contact uneven sections of the tubers. The machine was evaluated for performance and the results obtained show that the peeler drum grates at $30 \mathrm{rpm}$, an average mass of $8.610 \mathrm{~kg}$ of cassava was processed by the developed machine to produce an average $8.162 \mathrm{~kg}$ of properly peeled cassava, an average peeling time of $\mathbf{8 . 0 3 2}$ minutes, average percentage damage of $5.26 \%$, efficiency of $94.74 \%$, machine throughput capacity of $1.092 \mathrm{~kg} / \mathrm{min}$., and average damaged mass of $0.448 \mathrm{~kg}$ of cassava. Therefore, this research work has improved on an earlier developed cassava peeling machine by adding to its functionality and aesthetics using an innovative approach.
\end{abstract}

Keywords - Cassava, peeling machine, develop, efficiency, unpeel cassava.

\section{INTRODUCTION}

Cassava (Manihot Esculenta Cranti) originated from Brazil to the tropical areas of Africa, the East and the Caribbean island by the Portuguese during the 16th and 17th centuries. At present, cassava is one of the most important and widely cultivated crops in sub-Sahara Africa. Nigeria is currently the largest producer of cassava in the world with annual output of over 34 million tons of tuberous of roots [1-2]. The crop is mainly classified as sweet or bitter (manihot utilissima or manihot palmate) cassava respectively. Until recently, cassava is cultivated for food, as it is consumed on a daily basis in most sub-Sahara Africa countries homes, sometimes twice a day, but has recently gained serious industrial relevance both locally and internationally. Furthermore, before cassava can be consumed, the inedible part of the crop, otherwise known as the peel must be removed and further processed to reduce the toxic cyanogenic glycoside which is more concentrated in the peel.

Besides, cassava is a major source of carbohydrate when consumed. It is an important diet to more than eight hundred million $(800,000,000)$ people around the world [3]. Cassava is referred to as a food security crop [4] because it can stay unharvested for an extended period of up to two (2) years, until required. Cassava is used mainly as a fresh food item, but can be processed into various food and non-food products, such as starch, flour, beverages, animal feeds, bio-fuels and textiles [5]. It can be used as binder in the textile industries as well as in many pharmaceutical and agro allied industries. In Nigeria, the crop can be processed into garri, lafun, paki, pupuru, fufu and cassava grit for direct human/livestock consumption. It can also serve as raw material for the production of bread, biscuit and other consumable and non-consumable products. The commercial potential of cassava is currently underutilized in Nigeria, with an annual production capacity of 34 million tons of fresh tubers [6-8]. In Nigeria, it is eaten boiled; it can be pounded to be eaten with soup. Due to the economical viability and need for cassava, the Government of 


\section{International Journal of Engineering Applied Sciences and Technology, 2020 \\ Vol. 5, Issue 1, ISSN No. 2455-2143, Pages 74-84 \\ Published Online May 2020 in IJEAST (http://www.ijeast.com)}

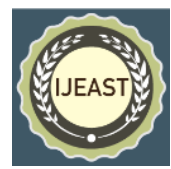

Nigeria and Ghana implemented a 'presidential initiatives' to increase cassava production for local consumption and export promotion [9]. Cassava has become one of the prominent crops that are required for both local consumption and export promotion. Apart from human consumption, cassava is also used for animal feed and alcohol production [10]. There is an increasing global demand for cassava chips and pellets, particularly in China and Brazil. Cassava can therefore be referred to as a multi-purpose crop for man and livestock.

Cassava tubers require immediate processing after harvest, because, they begin to deteriorate within 72 hours after harvesting, this is due to high water content in tubers [11-12]. The processing of cassava into usable forms require some or all the following step; peeling, washing, grating, pulverizing, fermenting, dewatering/pressing, frying and sometimes cooking. Of all these processes, peeling is the first and most important step in cassava processing. Traditionally, peeling is carried out by women and children using local matchets and knives. This process which involves an average woman peeling about $20-25 \mathrm{~kg}$ of roots per day is in itself slow, time consuming and unfit for large scale processing. Apart from being slow, manual peeling is characterized with a lot of drudgery, and high loss of useful flesh. An estimated $30 \%$ loss in useful flesh has been recorded through this process [13-15]. Even though manual peeling has a lot of shortcomings, because the various mechanical peeling machines developed have not been universally accepted, involves high cost and are not proven to have completely solved the peeling difficulty of farmers. Hence, most farmers are hesitant in applying these machines. It is on this backdrop this research is anchored, as another means of solving a teething problem.

\section{MATERIALS AND METHODS}

\section{A. Materials Selection}

In the selection of engineering materials for this project work, certain factors were considered. These include;

i. Whether the properties of the materials alter with time during services.

ii. Whether the materials can produce the necessary service (service requirement)

iii. Whether the materials will be acceptable on aesthetic ground (appearance of the finished goods)

iv. Materials availability (the materials should be readily available

v. It must be corrosion free because it would be used at all times and even in rain/water.

vi. How it expands when subjected to heat application.

vii. The finished product must have good surface finish.

viii. Materials suitability, that is the materials should be able to perform the intended function without failure.

ix. The cost of the materials; the materials should be relatively cheap

With the above mentioned qualities, a stainless steel material that possesses these qualities was selected. The stainless steel was used for the construction of the peeling chamber while galvanized steel is used for the construction of the frame and the body.

Stainless steel was selected because of the following properties;

i. Excellent corrosion resistance

ii. Price competitiveness and stability

iii. Good formability because of relative softness

iv. Excellent physical properties

v. Line up of various surface finishes

vi. More economically viable once service life and life cycle

Besides, strength of the materials used in this research work depends largely on the behavior of structural and machine members under the action of external loads taking into account the internal forces created and the resulting deformations. Analysis is directed towards determining the limiting loads which the members can stand before failure of the material or excessive deformation.

Some advantages of the strength of the materials selected includes;

$\begin{aligned} \text { i. } & \text { Malleability } \\ \text { ii. } & \text { Hardness } \\ \text { iii. } & \text { Ductility } \\ \text { iv. } & \text { Corrosion resistance } \\ \text { v. } & \text { Low unit stress } \\ \text { vi. } & \text { No preheat /post heat treatment }\end{aligned}$

\section{B. Basic Component of the Machine}

\section{$i$. The Pulley System}

The pulley system is basically the power transmission system. Two V-belt transmit power from the engine drive shaft to the first grater drive shaft with a sheave of four pulleys. Two other belts transmit. The available power to the second drive shaft. One belt transmits power from the other end of the first grater drive shaft to a speed reducer input shaft.

\section{ii. The Shaft}

The shafts incorporated in the machine are basically transmission shaft designed to transmit power from one point to another. The power is delivered to the shaft by some tangential forces and the resultant torque or (twisting movement) set up within the shaft permits the power to be transferred to the various linkages through the use of belts and pulleys mounted on it. The transmission shaft chosen are of solid shaft cross section made from carbon steel with high yield strength and whole members are mounted by means of keys.

\section{iii. Bearings}

Bearing is precision device used to support the shaft and permit relative motion between the contact surfaces of the members while carrying load. Six rolling contact bearing (ball bearings) are mounted on appropriate seating. A part from the other numerous advantages occurring from the choice, more importance is attached to its reliability in service nature of load (light and radial) and the high degree of anti-friction 


\section{International Journal of Engineering Applied Sciences and Technology, 2020 Vol. 5, Issue 1, ISSN No. 2455-2143, Pages 74-84 \\ Published Online May 2020 in IJEAST (http://www.ijeast.com)}

offered provision is made for periodical lubrication and replacement.

\section{iv. Presser Mechanism}

This mechanism converts a rotary motion of the crank to reciprocating motion of the presser. The mechanism consist of three turning pairs and one slider pair.

The turning pairs are;

a. The shaft turning in the bearing fixed to the frame.

b. The connecting rod and crank

c. Connecting rod and the presser.

The only slider pair is the presser and the slide way on the framework.

\section{v. Speed Reducer}

The functions of the speed reducer are as follows

a. To deliver the power at a lower speed to presser mechanism.

b. To transmit power through machine elements that reduces the rotational speed to a specific area.

c. To receive power from the input source (engine) through a rotating shaft.

\section{vi. Fasteners}

These are temporary or detachable fastening (bolts, nuts, keys screws etc.). They are employed for joints. Which can be used for assembling of the components or disassembling without destroying the components during repairs or maintenance. The major function of these fasteners is to make a connection that will ensure strength and tightness.

\section{vii. Base Support}

The base support is constructed from angle plate or angle iron and has been employed for a defined dual functions. First, it provides the base seating for all the machine accessories or entire assembly including the diesel engine. It also provides a link through which machine can be bolted to the foundation floor through the use of bolts and nuts in the slots provided effective rigidity and mounting.

\section{viii. The Framework}

The framework or body structure is entirely composed of mild steed plate. It is made up of about $0.15 \%$ to $0.45 \%$ carbon and suitable for this purpose because of its high strength, weld ability, malleability with some reasonable degree of corrosion resistance. $5 \mathrm{~mm}$ thick mild steel plate was used for every part of the body including the bearing seating.

\section{Design Consideration}

The following factors were considered;

\section{a. Food Product Considerations}

The quality and quantity of cassava peeled is also an important consideration for the process. To meet the quality demand of both domestic and industrial purposes, the chosen design will increase the current peeling rate as well as the integrity of the product. Currently, manual process of peeling is the common practice both in domestic and industrial arena with its attendant drudgery and losses. Changing the peeling machine mechanism may improve the outcome in terms of throughput capacity, product acceptability and the integrity. This consideration is taken seriously in effecting the design.

\section{b. Physical Considerations}

An additional set of design considerations are the materials used, the power sources, ease of operation, and maintainability.

\section{i. Power Sources}

Another consideration for the design is the power sources readily available in Nigeria. Because the cost of fuel is increasing dramatically, the importance of not depending on an expendable resource is evident. The possibility that this machine might be used in locations that do not have easy access to the National grid is also significant. For this reason the machine should have the option of being powered by a renewable source, hence the power consumption must be within values that can accommodate other sources of energy.

\section{ii. Ease of Operation}

Ease of operation is another essential physical consideration. The machines must be designed to be used easily by various types of operators. Also, the machines should be designed to make the new process similar to the current process.

\section{iii. Maintainability}

The maintainability of the final machine is also significant consideration in the design process. This issue is closely linked with the cultural appropriateness consideration addressed in the ethics section. To counter the cultural tendency to not repair machines, a physical design consideration is creating a machine that is easy to repair locally.

\section{iv. Reliability in Service}

A machine of this caliber must be reliable in service. Most of the products in the market are not having patronage partly due to reliability questions. Most farmers are of the view that these are unproven that may not be not solve the relevant problem. Hence farmers are hesitant to apply these for their operation. In addition, strength to withstand the various loads without failure is a key element in this design, especially for a system that will be subjected abuse by user as it is the practice most rural dwellers in Nigeria. Again, the machine shall be subjected vibrational forces, this call for toughness.

\section{c. Machining Considerations}

This applies to machine parameters the will affect the production of the propose peeling machine. All factors that will enhance effective construction of the machine, and it must be within available resources at our disposal. These factors 


\section{International Journal of Engineering Applied Sciences and Technology, 2020 \\ Vol. 5, Issue 1, ISSN No. 2455-2143, Pages 74-84 \\ Published Online May 2020 in IJEAST (http://www.ijeast.com)}

may include maintaining tolerances, ease of machining, and free relative motion of dynamic sub-assemblies.

\section{i. Ease of Machining}

One key factor in bringing a design into reality is the ability to fabricate the design with ease. The availability of a functional workshop, experienced operator and machines to fabricate within specify limits are key to the success of any engineering adventure. To achieve this, available means of fabricating the machine were considered during the design. As stated earlier, local fabricators shall be used, thus, the ease at which this can be achieved without compromising major features has been factored into this project.

\section{Design Calculation a. Drum Selection}

Few materials known to have performed as drum materials were selected based on chemical composition of cassava and material, durability and machinability.

* Aluminum: It may not react with HCN compounds making it suitable for the design.

* Galvanized Iron: This also, does not react with HCN, but for the purposes of weight, galvanized iron is preferred. Thus, it was selected.

* Stainless Steel: Is also another good material for the design, however, considering the cost.

Choosing a drum of $800 \mathrm{~mm}$ length and $450 \mathrm{~mm}$ in diameter;

Total surface Area $\left(\mathrm{A}_{\mathrm{s}}\right)=$ End Area + Surface Area of Longitudinal side

Fig. 1 shows the schematic diagram of the drum

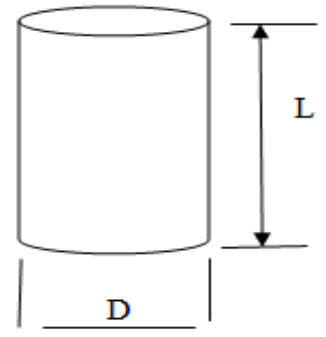

Fig. 1 Peeling Drum

$$
A_{s}=2 \times \pi \frac{d^{2}}{4}+2 \pi r L
$$

$\mathrm{A}_{\mathrm{s}}=1.4491 \mathrm{~m}^{2}$

According to Eugene and Theodore (1996), the mass of a drum, $m$ is given by:

$\mathrm{M}=\rho \mathrm{V}$

where;

$\rho=$ Density of material

$\mathrm{V}=$ Volume

Hence;
Volume of drum $\left(\mathrm{V}_{\mathrm{D}}\right)=$ Area of drum $\mathrm{x}$ thickness

$=\pi \mathrm{dt}(2 \mathrm{~d} / 4+\mathrm{d} \mathrm{L})$

$\mathrm{VD}=0.0028982 \mathrm{~m}^{3}=2.8982 \times 10^{-3} \mathrm{~m}^{3}$

Using Galvanized iron as material;

Mass of Drum, $\mathrm{M}_{\mathrm{D}}=7870 \times 2.8982 \times 10^{-3}=22.8808 \mathrm{~kg}$

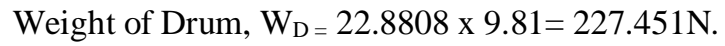

Whereas the rotation of the cassava will generate a centrifugal force, within the drum, the peeling process involves a tangential force, $F_{t}$.

Therefore;

$\mathrm{F}_{\mathrm{t}}=\mathrm{ma}_{\mathrm{t}}$

where,

$\mathrm{a}_{\mathrm{t}}=$ Tangential acceleration.

Average acceleration,

$\mathrm{a}_{\mathrm{t}}=\frac{\mathrm{v}+\mathrm{u}}{\mathrm{t}}$

where,

$\mathrm{U}=$ Initial and

$\mathrm{V}=$ Final velocities

But,

$\mathrm{U}=0$

Substituting Equation (5) into Equation (4) gives

$\mathrm{F}_{\mathrm{t}}=\mathrm{m}(\mathrm{v} / \mathrm{t})$

But,

$\mathrm{V}=\omega \times \mathrm{r}$

and

$\omega=\underline{2 \pi \mathrm{N}}$

$$
60
$$

But;

$\mathrm{V}=\frac{2 \pi}{60} \mathrm{Nr}$

where;

$\mathrm{N}=$ Speed (rev/min)

Adopting a speed of 50rpm, since, there evidences to support the argument that, lower speeds reduce mechanical damage and improves quality of peel [16-17].

Therefore;

$\mathrm{F}=\mathrm{mv} / \mathrm{t}=\frac{2 \mathrm{~m} \pi \mathrm{Nr}}{6}$

$\mathrm{F}_{\mathrm{t}}=\frac{2 \pi \times 22.8808 \times 0.225 \times 50}{60}$

$=227.451 \mathrm{~N}$

Hence;

Power required,

$\mathrm{P}_{\mathrm{rq}}=\mathrm{T} \omega$

Torque on shaft will be required to rotate both drum and the cassava tubers; therefore, combined load on shaft, $\mathrm{P}_{\mathrm{c}}$ shall be;

Combined load,

$\mathrm{Pc}=500+227.451=727.451 \mathrm{~N}$

Torque required,

$\mathrm{T}_{\mathrm{r}}=\mathrm{F} \times \mathrm{r}$ 
$\mathrm{T}_{\mathrm{r}}=727.451 \times 0.225 \mathrm{~m}=163.6765 \mathrm{Nm}$

Angular Velocity $(\omega)$;

$\omega=\frac{2 \pi \times 50}{60}$

$\omega=5.325 \mathrm{rad} / \mathrm{s}$

Power, $\mathrm{P}_{\text {req }}$

$\mathrm{P}_{\text {req }}=163.6765 \times 5.326=871.741 \mathrm{~W}$.

Mass of cassava per batch $=50 \mathrm{~kg}$

Total load $=500 \mathrm{~N}$

Using a factor of safety of 1.5

Total allowable load $=750 \mathrm{~N}$

\section{Shaft Design}

The design requirements are:

i. A shaft with adequate strength to withstand impact or shock loads from cassava loading

ii. Strength to accommodate turning moment and fluctuations from loads.

iii. Shaft material that will not deteriorate on contact with cassava flour over acceptable number of cycles (i.e. 100,000 cycles).

Length of shaft can be deduced from the equation below:

Length of shaft $=$ length of drum +2 (bearing thickness) $+2 \mathrm{x}$ (end pulley) $=1150 \mathrm{~mm}$

Since, the shaft will be subjected to changes in speed and power fluctuations, the most appropriate approach to the design are for fluctuating stresses;

Distortion energy failure theory, the Von Mises stresses for rotating round, solid shafts, neglecting axial loads, are given by:

$\sigma_{a}^{1}=\left(\sigma_{a}^{2}+3 T_{a}^{3}\right)^{1 / 2}=\left[\frac{\left(32 K_{f} M_{a}\right)^{2}}{\bar{\pi} d^{3}}+3 \frac{16 K_{f} T_{a}}{\pi d^{3}}\right]^{1 / 2}$

$\sigma_{m}^{1}=\left(\sigma_{m}^{2}+3 T_{n}^{2}\right)^{1 / 2}=\left[\frac{\left(32 K_{f} M_{n}\right)^{2}}{\bar{\pi} d^{3}}+3\left(\frac{16 K_{f} T_{m}}{\pi d^{3}}\right)\right]^{1 / 2}$

For a shaft subjected to combine torsion and bending, under fluctuating loads;

Twisting moment,

$\mathrm{T} \omega=\sqrt{(\mathrm{kmx} \mathrm{M}) 2+\left(\mathrm{kt}+\mathrm{T}^{2}\right) 2}$

Bending moment is given by Equation (16) [18]

$\mathrm{M}_{\mathrm{b}}=1 / 2\left[\mathrm{~K}_{\mathrm{M}} \times \mathrm{M}+\left(\mathrm{k}_{\mathrm{m}} \times \mathrm{M}\right)^{2}+\left(\mathrm{k}_{\mathrm{T}} \times \mathrm{T}\right)^{2}\right]$

where,

$\mathrm{K}_{\mathrm{m}}=$ Combined shock and fatigue factor for bending

$\mathrm{K}_{\mathrm{T}}=$ Combined shock and fatigue factor for torsion

Therefore,

Size of shaft can be computed from the following;
Torque $=163.6765$

Moment,

$\mathrm{M}=\frac{\mathrm{WL}}{4}$

where;

$\mathrm{L}=$ Length of shaft

$\mathrm{M}=\underline{750 \times 1.15}$ 4

$=215.625 \mathrm{Nm}$

Therefore;

$$
\begin{aligned}
& T_{M}=\sqrt{\left.M^{2}+T^{2}\right)} \\
= & \sqrt{215.625^{2}+163.6765^{2}} \\
= & 270.7104 \mathrm{Nm}
\end{aligned}
$$

But allowable shear stress for shaft in torsion is $210 \mathrm{MPa}$.

Thus;

$\tau \mathrm{d}^{3} / 16=270.7104$

$\mathrm{d}^{3}=6.58996 \times 10^{-6}$

$\mathrm{d}=0.0187=18.74 \mathrm{~mm}$

Thus, a shaft diameter of $20 \mathrm{~mm}$ was used.

For Bending

$M_{b}=1 / 2\left[215.625+\sqrt{215.625^{2}+163.6765}\right.$

$=243.1677 \mathrm{Nm}$

$\pi / 32 \tau \mathrm{d}^{3}=243.1667$

But, allowable stress for bending $=410 \mathrm{MPa}$.

Hence,

$\pi / 32 \times 210 \times 10^{6} \mathrm{~d}^{3}=243.1667$

$\mathrm{d}^{3}=6.04116 \times 10^{-6}$

$\mathrm{d}=0.01821 \times 10^{2}=18.21 \mathrm{~mm}$

$20 \mathrm{~mm}$ diameter shaft was used

Since the condition for torsion gives a higher shaft diameter, of $20 \mathrm{~mm}$, for manufacture; use $20 \mathrm{~mm}$.

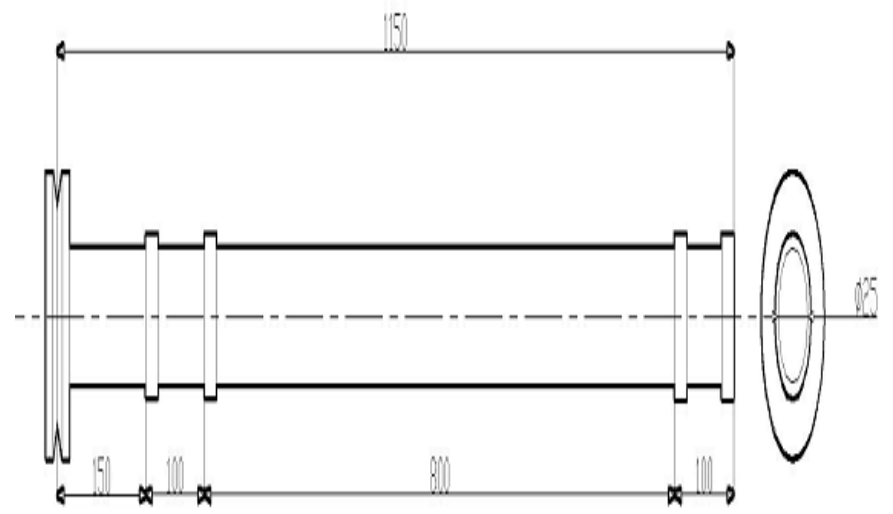

Fig. 2 Shaft Arrangement

Electric Motor Selection 


\section{International Journal of Engineering Applied Sciences and Technology, 2020 \\ Vol. 5, Issue 1, ISSN No. 2455-2143, Pages 74-84 \\ Published Online May 2020 in IJEAST (http://www.ijeast.com)}

Considering the value of force the belt is subjected, that is $703.45 \mathrm{~W}$, the required horse power for the electric motor can determined as follows;

Power, $\mathrm{P}=703.45 / 0.75=0.938 \mathrm{hp}$

Therefore $1 \mathrm{hp}$ power elector will be required to drive the shaft and drum assembly, however, since the value is quite close to the $1 \mathrm{hp}$, for a machine that will be subjected to variable loading, also drop due friction and machine efficiency losses, a $1.5 \mathrm{hp}$ motor is recommended.

\section{Design Spur gears Specification}

Design for speed reducer

Power to be delivered $=1 \mathrm{hp}$

Input speed $=1500 \mathrm{rpm}$

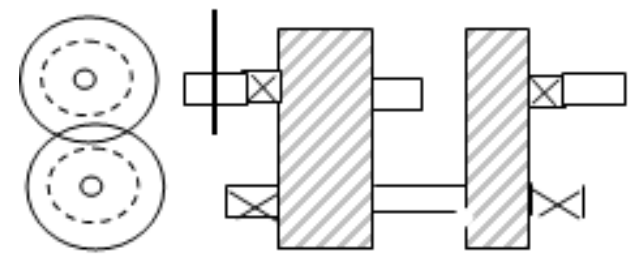

Fig. 3 Spur Gear Arrangement

Input speed $=60 \mathrm{rpm}$

Require low shock levels

Output shaft and input shaft in-line

Gearbox and bearing life $=30,000 \mathrm{hrs}$

Maximum gearbox size:

$50 \mathrm{rpm}<\mathrm{w}<60 \mathrm{rpm}$

Using the notation for gear number from fig 18.1 choose mean value for initial design as $55 \mathrm{rpm}$

$e=\frac{\omega_{a v}}{\omega_{i n}}=\frac{55}{1500}=0.0367=\frac{I}{27.273}$

For a compound reverted gear train (ratio)

$e=\frac{I}{27.273}=\frac{N_{2}}{N_{3}} \quad \frac{N_{4}}{N_{5}}$

For smallest package size, let both stages be the same. Also, by making the two stages identical, the in-line condition on the input and output shaft will automatically be satisfied.

$$
\frac{N_{2}}{N_{3}}=\frac{N_{4}}{N_{5}}=\sqrt{\frac{1}{27.273}}=\frac{1}{5.222}
$$

For the ration the minimum No for teeth from smallest No of teeth $\mathrm{N}_{\mathrm{p}}$ on pinion without interference is given by:

$N p=\frac{2 k}{(1+2 m)\left(\sin ^{2} \phi\right)}\left[m+\sqrt{m^{2}+}(1+2 m) \sin ^{2} \phi\right]$

where,

$\mathrm{m}=$ module $\phi=$ pressure angle,

$\mathrm{k}=1$

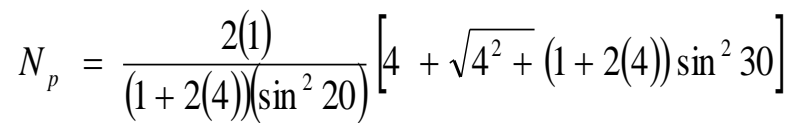

$=18=19$ teeth

Minimum of teeth for non-interference $=16$

$\mathrm{N}_{2}=\mathrm{N}_{4}=16$

$\mathrm{N}_{3}=5.222(16)=83.552=84$

Check, if $\omega_{5}$ is within limits:

$\omega_{5}=\left(\frac{16}{84}\right)\left(\frac{16}{84}\right)(1500)=54.422$ acceptable

$\mathrm{N}_{2}=\mathrm{N}_{4}=16$

$\mathrm{N}_{3}=\mathrm{N}_{5}=84$

$e=\left(\frac{16}{84}\right)\left(\frac{16}{84}\right)=\frac{1}{27.565}$

$\omega_{5}=54.427 \mathrm{riv} / \mathrm{min}$

But;

$\omega_{3}=\omega_{4}=\left(\frac{16}{84}\right) \times 1500=285: 714 \mathrm{rev} / \mathrm{min}$

To determine the torques, we return to power relationship $\mathrm{H}=\mathrm{T}_{2} \omega_{2}=\mathrm{T}_{5} \omega_{5}$

$T_{2}=H / \omega_{2}=\frac{1.5}{1500}\left(\frac{60}{2 \pi}\right) \times 750=7.162 \mathrm{Nm}$

$T_{3}=T_{2} \frac{\omega_{2}}{\omega_{3}}=7.162\left(\frac{1.5}{285.714}\right)=37.60 \mathrm{Nm}$

$T_{5}=7.162\left(\frac{1500}{54.722}\right)=T_{2} \frac{\omega_{2}}{\omega_{5}}=197.197 .402 \mathrm{Nm}$

Factor of safety required $=1.5$, gearbox height $=0.50 \mathrm{~m}$ Hence,

Minimum diametral pitch, $P_{\min }=\frac{\left(N_{3}+N_{5} / 2+2\right)}{\gamma \text {-clearanace - wall thickness }}$

Allow $2 \mathrm{~mm}$ for clearance and wall thickness

$P_{\min }=\frac{\left(84+\frac{16}{2}+\frac{84}{2}+2\right)}{0.50-0.005-0.005}=0.35$ teeth $/ \mathrm{mm}$

$d_{2}=d_{4}=\frac{16}{0.4}=40 \mathrm{~mm}$

$d_{5}=d_{3}=\frac{84}{0.4}=210 \mathrm{~mm}$

With a start of 0.4 teeth $/ \mathrm{mm}$

Initial shaft speeds calculated are:

$\omega_{2}=1500 \mathrm{rev} / \mathrm{mm}, \omega_{3}=\omega_{4}=285.714 \mathrm{rpm}$ 


\section{International Journal of Engineering Applied Sciences and Technology, 2020 \\ Vol. 5, Issue 1, ISSN No. 2455-2143, Pages 74-84 \\ Published Online May 2020 in IJEAST (http://www.ijeast.com)}

$\omega_{5}=55.422 \mathrm{rpm}$

To get pitch velocities and transmitted loads:

$V_{23}=\omega_{2} x r$

$$
=\omega_{2} \times d / 2=\frac{2 \pi \times 1500}{60} \times 0.20=3.142 \mathrm{~m} / \mathrm{s}
$$

$V_{45}=\frac{2 \pi 54.422}{60} \times 0.105=0.5098 \mathrm{~m} / \mathrm{s}$

Load,

$\mathrm{P}=1.5 \mathrm{hp}=1.125 \mathrm{KW}$

$P_{23}=\frac{1.125}{3.142}=0.358 K N=358 N$

$P_{45}=\frac{1.125}{0.598}=1.881 \mathrm{KN}$

$\mathrm{Q}_{\mathrm{v}}=$ Transmission accuracy level

$Y_{N}=$ Stress cycle factor for bending

$\mathrm{Z}_{\mathrm{N}}=$ Stress cycle factor putting resistance

I (putting resistance)

\section{Gear Wear}

Geometry factor for both spur and helical gears as given as;

$I=\frac{\operatorname{Cos} \phi_{t} \sin \phi_{t}}{2 M_{N}} \frac{M_{G}}{M_{G}+1}-$ external gears

$I=\frac{\operatorname{Cos} \phi_{t} \sin \phi_{t}}{2 M_{N}} \frac{M_{G}}{M_{G}+1}-$ int ernal gears

where

$\mathrm{M}_{\mathrm{N}}=$ Load sharing ratio

$\mathrm{M}_{\mathrm{G}}=$ Gear ratio

$\phi_{\mathrm{T}}=$ Transverse pressure angle

$\mathrm{M}_{\mathrm{G}}=5.25$

$\mathrm{M}_{\mathrm{N}}=1.0$ for spur \& helical gears,

$\phi_{t}=20$.

$I=\frac{\operatorname{Cos} 20^{\circ} \sin 20^{\circ}}{2(1)} \times \frac{5.25}{5.25+1}=0.1234$

ANSI/AGMA 908, B89 (2001)

For $\mathrm{K}_{\mathrm{V}}=$ Assume $\mathrm{Q}_{\mathrm{v}}=9$ and $\mathrm{A}=2.4715$

$$
\begin{aligned}
& \operatorname{Max} V=\frac{[A+(Q v-3)]^{2}}{200}= \\
& (0.2094 \times 200)^{1 / 2}=A+7-3
\end{aligned}
$$

$\mathrm{A}=2.4715$

$$
\begin{aligned}
K_{V} & =\left(\frac{2.4716+\sqrt{0.598}}{2.4715}\right)^{0.731} \\
& =1.22
\end{aligned}
$$

\section{Bearing Selection}

Since the shaft is rotating and making constant contact with the bearing, the required bearing type shall be a rolling contact bearing.

Axial load, $\mathrm{W}_{\mathrm{A}}=304 \mathrm{~N}$ and Radial load, $\mathrm{W}_{\mathrm{R}}=304.25 \mathrm{~N}$

Assuming a lifespan of 6 years for the bearing and 8 hours working time per day for 310 days per year gives, the life of the bearing in hours, $\mathrm{L}_{\mathrm{h}}$ as;

$\mathrm{L}_{\mathrm{h}}=6 \times 310 \times 8=14,880 \mathrm{hrs}$

The life of the bearing in revolution is obtained using the maximum revolution of the shaft.

$\mathrm{LR}=6 \times 225 \times 14880=20.038 \times 10^{6} \mathrm{rev}$

The dynamic equivalent radial load, $W_{D}$ is given by the relationship given below.

$\mathrm{W}_{\mathrm{D}}=\mathrm{XVW}_{\mathrm{R}}+\mathrm{YW}_{\mathrm{A}}$

In order to determine the radial and axial load factors, we need $\mathrm{W}_{\mathrm{A}} / \mathrm{W}_{\mathrm{R}}$ and $\mathrm{W}_{\mathrm{A}} / \mathrm{C}_{\mathrm{o}}$,

where,

$\mathrm{C}_{\mathrm{o}}=$ Static load capacity factor

For deep groove ball bearing, the maximum value of $\mathrm{W}_{\mathrm{A}} / \mathrm{C}_{\mathrm{o}}=$ 0.50 .

Therefore, assuming the maximum value gives rise to a maximum ratio of $\mathrm{W}_{\mathrm{A}} / \mathrm{W}_{\mathrm{R}}=0.999$.

But,

$\mathrm{X}=0.56$, and $\mathrm{Y}=1.0$

Since the rotational factor $(\mathrm{V})$ for most of the bearing is one, then, the dynamic equivalent of the radial load is;

$\mathrm{W}_{\mathrm{D}}=0.56 \times 1.0 \times 304+1.0 \times 304.25=474.50 \mathrm{~N}$

Checking SKF values for fatigue load for a shaft of $\Phi 25 \mathrm{~mm}$ that corresponds to the calculated value, a bearing of designation universally match-able are; 7205BECBPH, $7205 \mathrm{BECBM}$ and basic design bearing of 7305BEY is selected.

\section{Bolt Diameter Calculation}

The bolt material is cast Iron

$\sigma_{\mathrm{t}}=35 \mathrm{MPa}=35 \mathrm{~N} / \mathrm{mm}^{2}$

$\mathrm{E}=110 \mathrm{KN} / \mathrm{mm}^{2}$

$\mathrm{n}=4$

$\mathrm{W}=1.324 \mathrm{KN}$

$\mathrm{d}_{\mathrm{c}}^{2}=16 \underline{\mathrm{x} 1.324 \times 10^{3}}$

$=16.054 \mathrm{~mm}^{2}$

$\mathrm{d}_{\mathrm{c}}=4.007 \mathrm{~mm}$, use M6 bolts for end connections

\section{E. Description of the Machine}

The cutting process is an abrasive operation with the introduction of some form of gyroscopic motion. The machine 


\section{International Journal of Engineering Applied Sciences and Technology, 2020 \\ Vol. 5, Issue 1, ISSN No. 2455-2143, Pages 74-84 \\ Published Online May 2020 in IJEAST (http://www.ijeast.com)}

is actuated at two different points; both can operate independently to effect some degree of peeling. The first section is the upper frame that carries reducer gear electric motor of $3 \mathrm{hps}$, and it operates the drum assembly. This motor effects rotational motion to the peeler drum (inner drum) and also increase the rocking motion of entire drum assembly with the help of two cams underneath the drum assembly. The drum assembly has a capacity of $50 \mathrm{~kg}$ of cassava. The upper assembly alone is capable of peeling cassava at appropriate rate, but for better performance the complete system is required. Details of machine is shown in Fig. 4. The second part is the lower frame that carries both the drum assembly and upper frame. This section introduces a revolution motion to both the drum assembly and upper frame using a different electric motor. The combination of these three motions increases the level of agitation in the drum and also increases the abrasion action in all directions.

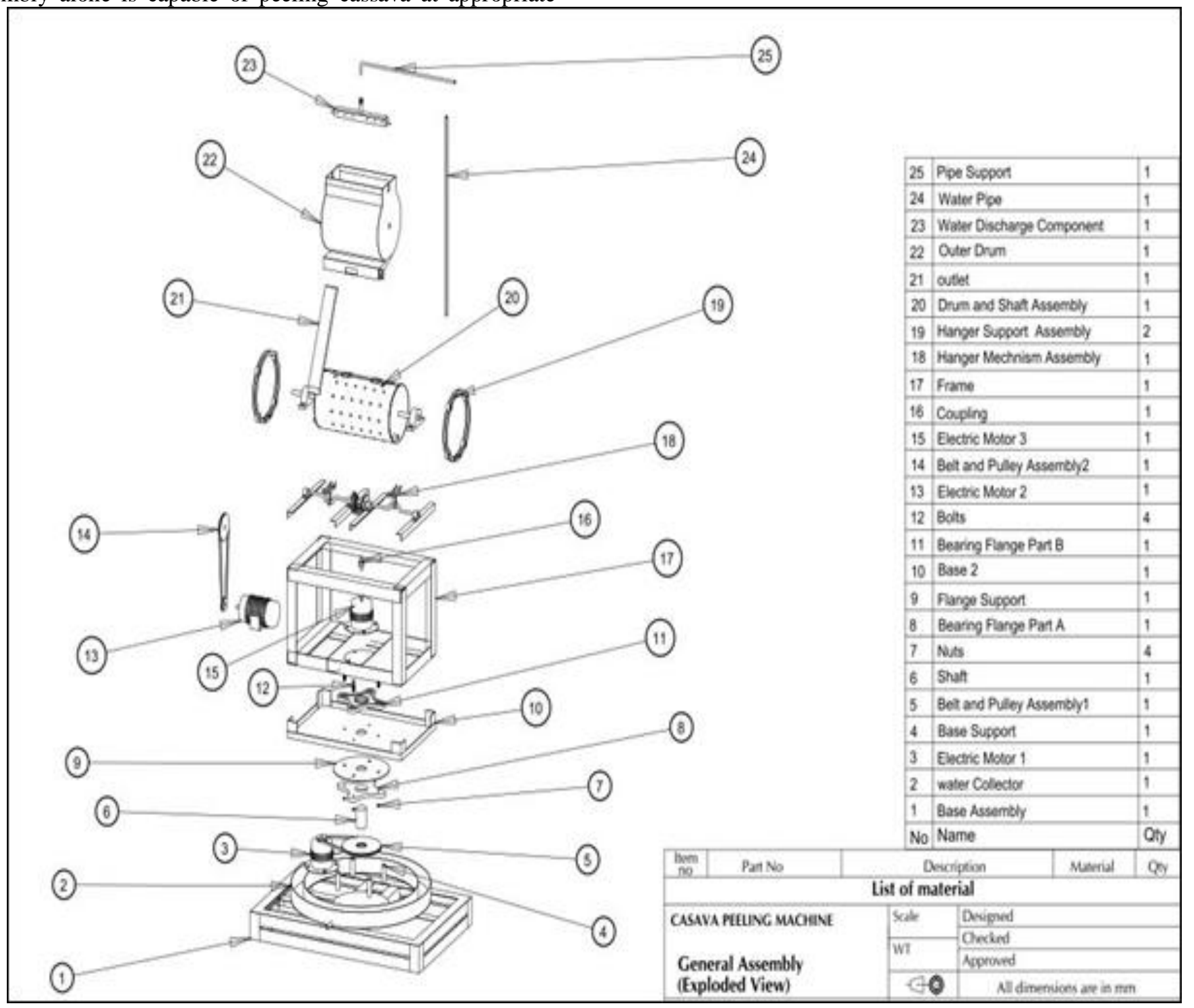

Fig. 4 Exploded View of Developed Cassava Peeling Machine

Fig. 5 shows the fabricated cassava peeling machine. 
International Journal of Engineering Applied Sciences and Technology, 2020

Vol. 5, Issue 1, ISSN No. 2455-2143, Pages 74-84

Published Online May 2020 in IJEAST (http://www.ijeast.com)

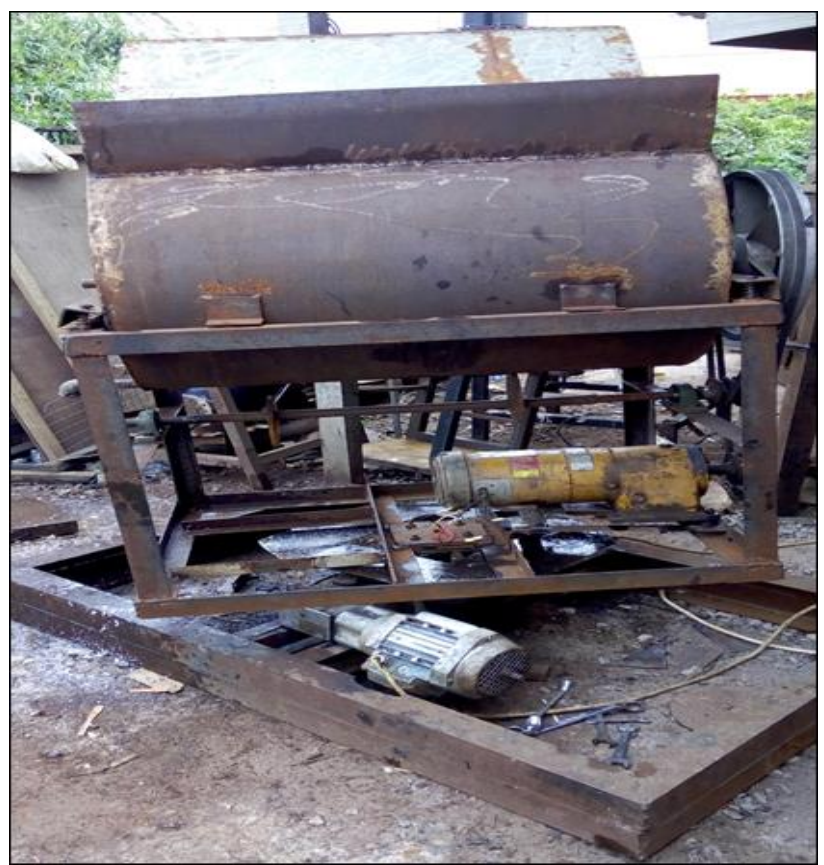

Fig. 5 Fabricated Cassava Peeling Machine

\section{EXPERIMENT AND RESULT}

The machine operates using electricity once it is switched on; the inner drum rotates while the upper frame and the drum revolve by the action of electric motion installed on the base frame. Preliminary investigation of the peeling process was conducted using few cassava tubers. The unpeeled tubers were placed inside the drum and machine operated to examine the extent of peeling carried out. Some level of improvement in peeling was observed. Finally, the tuber resident time in the drum was extended. During this peeling process, water was constantly introduced into the drum to improve the integrity and enhance peel removal. Five successive tests with varying masses of cassava tubers were used to carry out performance test on the machine. The peeling time, efficiency, machine throughput capacity and percentage breakage were all evaluated. Table 1 shows the results obtained. Fig. 6 shows the plot of different mass of cassava against number of tests carried out. As shown, large quantities of cassava were properly peeled. However, small portion of the cassava were damaged. This results agreed with the research work of [19] that also reported useful fresh loss from their research work. The damaged that was recorded could be as a result of abrasiveness of the peeling element considering the softness of cassava tubers. Fig. 7 shows graph of efficiency, peeling time, percentage damage, machine throughput capacity against

number of tests carried out.

The value of efficiency obtained throughout was approximately $95 \%$. With such high efficiency, the machine performance is satisfactory. Also, a low percentage damages were recorded throughout the test with an improved machine throughput capacity. Fig. 8 shows the bar chart of average values of mass of cassava, mass of peeled cassava, mass of damage cassava, peeling time, efficiency, machine throughput capacity, and percentage damage. Fig. 8 shows the average value of mass of cassava, mass of properly peeled cassava, mass of damaged cassava, percentage damage, peeling time, and machine throughput capacity. From the results outcome, an average mass of $8.610 \mathrm{~kg}$ of cassava was processed by the developed machine to produce an average $8.162 \mathrm{~kg}$ of properly peeled cassava, an average peeling time of 8.032 minutes, average percentage damage of $5.26 \%$, efficiency of $94.74 \%$, machine throughput capacity of $1.092 \mathrm{~kg} / \mathrm{min}$., and average damaged mass of $0.448 \mathrm{~kg}$ of cassava. With minimal damage mass of cassava recorded, and high efficiency obtained from the developed machine, the performance of the machine is satisfactory.

Table 1 Performance Test Results

\begin{tabular}{|l|l|l|l|l|l|l|l|}
\hline Test & $\mathrm{M}_{1}(\mathrm{~kg})$ & $\mathrm{M}_{2}(\mathrm{~kg})$ & $\mathrm{M}_{3}(\mathrm{~kg})$ & $\eta$ & $\mathrm{PT}$ & $\% \mathrm{D}$ & $\mathrm{MTC}(\mathrm{Kg} / \mathrm{Min})$. \\
\hline 1 & 10.05 & 9.51 & 0.54 & 94.63 & 10.12 & 5.37 & 0.99 \\
\hline 2 & 10.00 & 9.49 & 0.51 & 94.50 & 9.99 & 5.50 & 1.00 \\
\hline 3 & 8.45 & 7.98 & 0.47 & 94.44 & 7.85 & 5.56 & 1.08 \\
\hline 4 & 7.55 & 7.15 & 0.40 & 94.70 & 6.55 & 5.30 & 1.15 \\
\hline 5 & 7.00 & 6.68 & 0.32 & 95.43 & 5.65 & 4.57 & 1.24 \\
\hline$\sum$ & 43.05 & 40.81 & 2.24 & 473.70 & 40.16 & 26.30 & 5.46 \\
\hline Ave. & 8.610 & 8.162 & 0.448 & 94.74 & 8.032 & 5.26 & 1.092 \\
\hline
\end{tabular}

$\mathrm{M}_{1}=$ Mass of Unpeeled Cassava, $\mathrm{M}_{2}=$ Mass of Properly Peeled Cassava, $\mathrm{M}_{3}=$ Mass of damaged Cassava, $\eta$ = Efficiency, MTC = Machine Throughput Capacity, $\mathrm{PT}=$ Peeling Time, $\% \mathrm{D}=$ Percentage Damage, 


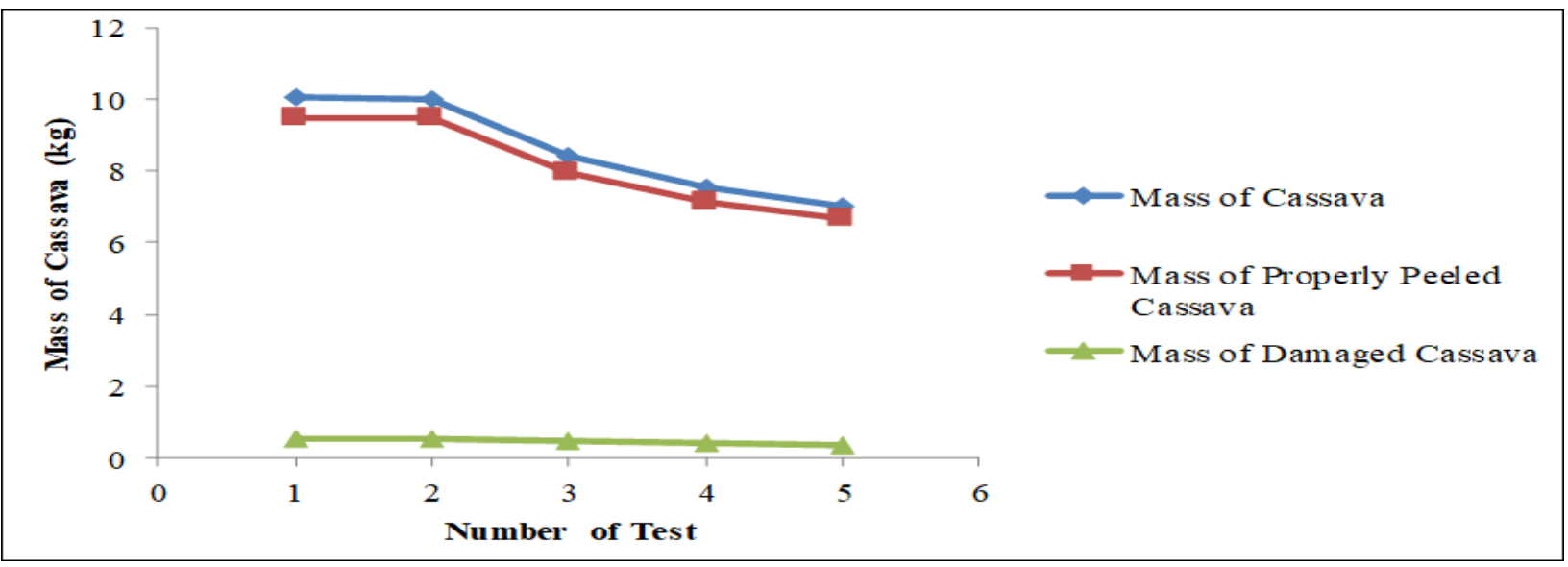

Fig. 6 Graph of Mass of Cassava against Number of Tests carried out

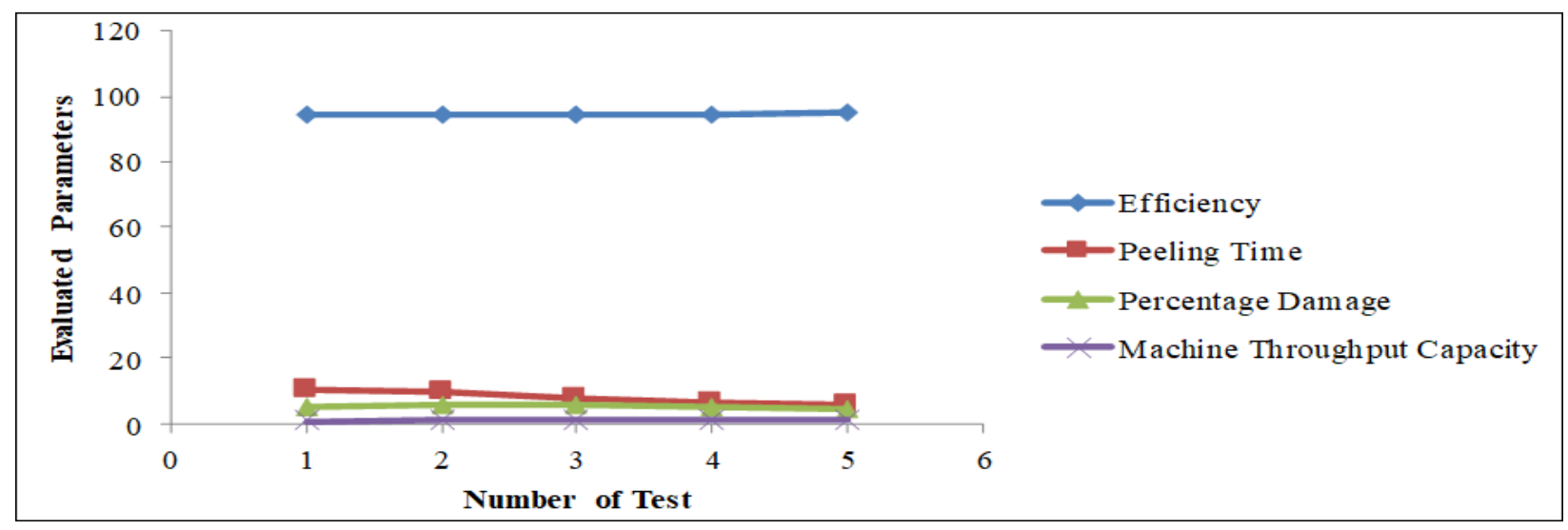

Fig. 7 Graph of Efficiency, Peeling Time, Percentage Damage, and Machine Throughput Capacity against Number of Tests

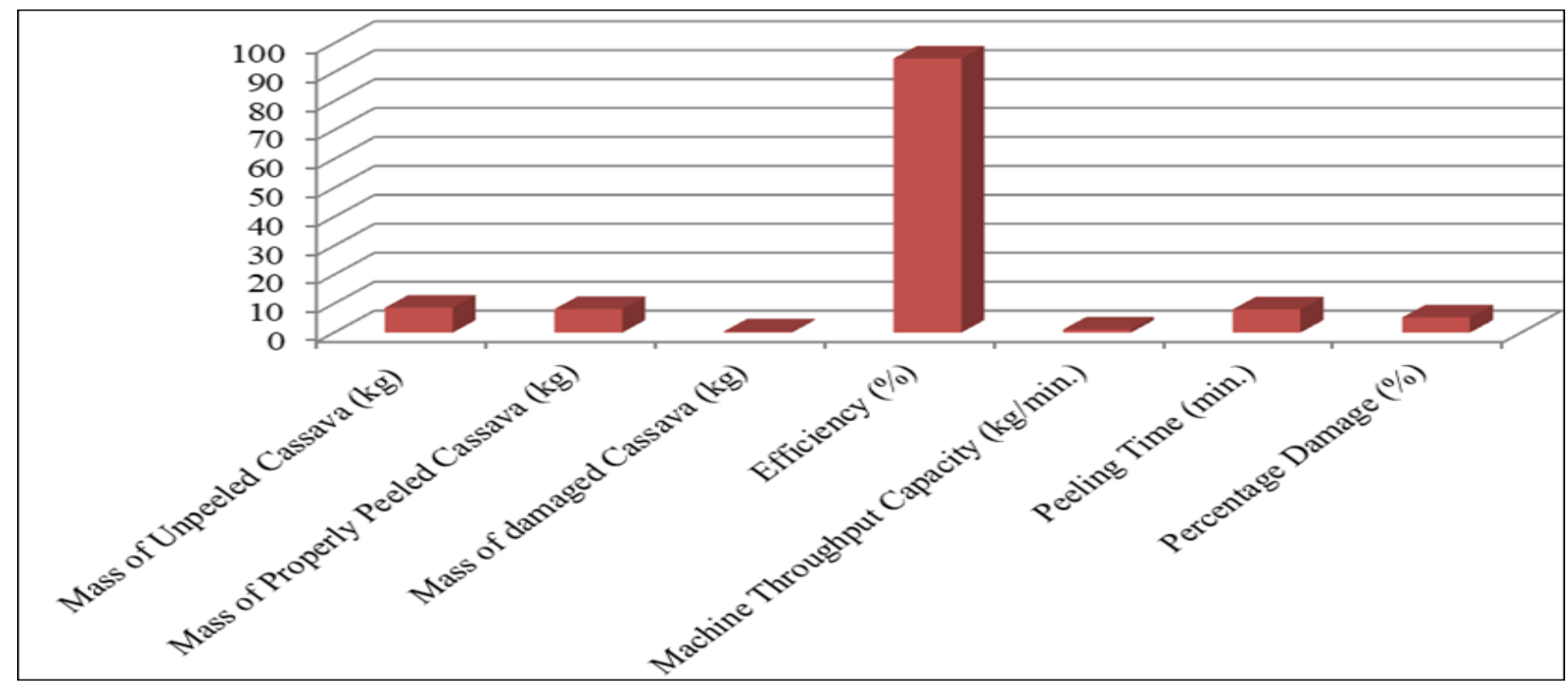

Fig. 8 Bar Chart of Average Values of Evaluated Paramete 


\section{International Journal of Engineering Applied Sciences and Technology, 2020 \\ Vol. 5, Issue 1, ISSN No. 2455-2143, Pages 74-84 \\ Published Online May 2020 in IJEAST (http://www.ijeast.com)}

\section{RECOMMENDATION}

The following is recommended;

i. Researchers should try to use more than one more peeling tool on the same peeling machine for efficient peeling.

ii. Future work should incorporate electronic automation system to enhance efficiency.

iii. More energy saving machines should be examined for future development.

\section{CONCLUSION}

This research work was set out to develop a cassava peeling machine that will peel all sizes and shape of cassava using an innovative approach, using locally available materials and fabrications to manufacture the machine. A substantial improvement was made to the cassava peeling machine with the use of stainless steels. This indeed is an improvement on the old peeler which was made of mild steel. This current one can stand the test of time as the results obtained are not only tight-fitting but also figure hugging.

\section{REFERENCE}

[1] Ohwovoriole, EN, Obi, S, and Mgbeke, ACC, (1988), Studies and preliminary design for a cassava tuber peeling machine, Transactions of the ASAE, Vol.31, No.2, (pp.380-385)

[2] Orhorhoro, EK, Orhorhoro, OW, Atumah, VE, (2017), Design and Development of an Improved Continuous Cassava Peeling Machine, North Asian International Research Journal of Sciences, Engineering \& I.T, Vol. 3, Issue 6, (pp. 1-18)

[3] Food and Agriculture Organization of the United Nations) Yearbook, (2007). Website:www.fao.org.

[4] Aravie, GO, and Ejovo, ON, (2002), Improved Ohwovoriole's rotary cassava tuber peeling machine, Nigerian Journal Engineering Research and Development, vol. 1(2), (pp. 61-63)

[5] Ceballos, H, Iglesias, AC, Perez, JC, and Dixon, A, (2004), Cassava breeding: opportunities and challenges. Plant. Mol. Biol., 56, (pp.506-516)

[6] Adetan, D.A, Adekoya LO, and Aluko, O.L, (2006), Theory of a mechanical method of peeling cassava tubers with knives. International Agrophysics, 20, (pp.269-276)

[7] Williams, SH, Wright, BW, Truong, V, Daubert, CR, Vinyard, CJ, (2005), Mechanical properties of foods used in experimental studies of primate masticatory function, American Journal of Primatology 67, (pp. 329-346)

[8] Davies, AM, Olatunji, MO, Burubai, W, (2008), A survey of cassava processing machinery in Oyo State, World
Journal of Agricultural Sciences No.4,Vol.3, (pp. 337340)

[9] Adepoju, OT, Adekola, YG, Mustapha, SO, and Ogunola, SI, (2010). Effect of processing methods on nutrient retention and contribution of cassava (manihot spp) to nutrient intake of Nigerian consumers, Afr. J. Food Agric. Nutr. Dev. 10(2), (pp.2099-2111)

[10] Akintunde, BO, Oyawale, FA, and Tunde-Akintunde, TY, (2005), Design and fabrication of a cassava peeling machine, Nigerian Food Journal. Vol. 23, (pp 1-8)

[11]Ejovo ON, Oboli, S and Mgbeke, ACC, (1988), Studies and preliminary design for a cassava tuber peeling machine. Transactions of the American Society of Agric. Engineers,31(2), (pp.380-385)

[12] Sheriff, JT, Kurup, GT, and Nanda, SK, (1995), Performance evaluation of cassava peeling machine. J. Root Crops 21(1), (pp.30-35)

[13] Kolawole OP, Agbetoye, LAS, and Ogunlowo, AS, (2010), Sustaining world food security with improved cassava processing technologies, The Nigerian Experience Sustainability, 2, (pp. 3681- 3694)

[14] Nwokedi, PM, (1984), Performance evaluation of cassava peeling machine. In: Tropical root crops: Production and uses in Africa, Int. Development Research Centre, pp. 108-110

[15] Olukunle OJ, and Adesina, A, (2004), "Development of a hand-fed cassava peeling machine, Exhibit of Research product, The First Nigerian Universities and Development Fair, Abuja, Nigeria

[16]Adetan DA, Adekoya, LO, Aluko, OB, and Mankanjuola,GA, (2005), An experimental mechanical cassava tubers peeling Machine. Journal of Agriculture Engineering and Technology' (JAET) vol. 13

[17] Olukunle, JO, and Akinnuli, OB, (2013), Theory of an automated cassava peeling system, International Journal of Engineering and Innovation Technology, Vol. 1 (5), (pp.5-8)

[18] Khurmi, RJ, and Gupta, JK, (2013), Machine Design, Eurasia Publishing House (pvt) Ltd, New Delhi, (pp. 731739)

[19] Orhorhoro, EK, Orhorhoro, OW, Ikpe, AE, A. Ngbeneme (2016), Analysis of Continuous Cassava Peeling Machine Design for Domestic and Commercial Use in Nigeria, J. of the Nigerian Association of Mathematical Physics, , Volume 36, Issue 2, (pp.443-448) 